Gut, 1980, 21, 537-540

\title{
Simultaneous cancer of the pancreas occurring in husband and wife
}

\author{
L J FERGUSON AND J MCK WATTS
}

From the Department of Surgery, Flinders Medical Centre, Bedford Park, South Australia, Australia

SUMMARY The simultaneous occurrence of cancer of the pancreas in husband and wife is reported. Both patients shared two dietary idiosyncrasies-namely, (1) the ingestion of copious amounts of margarine in which they cooked all their food and (2) the addition of 'coffee syrup', a liquid concentrate of coffee, to their ground coffee before percolation. The possible role of the latter in the aetiology of pancreatic cancer is discussed.

\section{Case histories}

THE WIFE

Mrs P D was a 64 year old housewife who presented in January 1977 with a six week history of epigastric pain radiating to the back, lassitude, anorexia, nausea, and occasional vomiting. For three weeks she had been jaundiced and had had pale stools and dark urine.

The patient had emigrated from Holland to Australia in 1957 and her only previous illness was bronchial asthma, which had resolved after her arrival in Australia. She did not smoke and took virtually no alcohol. She took an occasional sleeping tablet only, and had used an inhaled bronchodilator years previously. She lived with her husband and there was nothing unusual about their life-style. Their diet was unusual in only two respects: all dishes were cooked using large amounts of margarine and they almost always added 'coffee syrup' to their coffee before percolation.

\section{Examination}

The patient showed evidence of recent weight loss and mild icterus. The abdomen was soft with the liver easily palpable three finger-breadths below the right costal margin. There was no abdominal mass or ascites. Rectal examination was normal. Cardiovascular and respiratory systems were normal. Blood pressure was $140 / 70 \mathrm{mmHg}$. No other abnormalities were found.

\section{Investigations}

Urinalysis showed urobilinogen ++++ . Bile + . No glycosuria. Hb $13 \cdot 2 \mathrm{~g} / \mathrm{dl}$ WCC 10200 . Coagulation studies normal. Electrolytes, urea and plasma glucose were normal. Total protein $69 \mathrm{~g} / \mathrm{l}$ $(\mathrm{n}=60-80)$, albumin $40 \mathrm{~g} / \mathrm{l} \quad(\mathrm{n}=32-48)$, bilirubin $58 \mu \mathrm{mol} / \mathrm{l} \quad(\mathrm{n}=20 \mu \mathrm{mol} / \mathrm{l})$, alkaline phosphatase $480 \mathrm{U} / \mathrm{l}(\mathrm{n}=100-125)$, alanine transferase $96 \mathrm{U} / \mathrm{l}$ $(n=0-30 \mu / 1$ serum amylase $580 \mathrm{U} / 1(\mathrm{n}=10-300 \mu / 1)$. Radiographs of the chest were normal. Ultrasound scan of abdomen confirmed the dilatation of the intrahepatic ducts and showed multiple echoes on the gall bladder suggesting stones. Percutaneous transhepatic cholangiography showed gross dilatation of intrahepatic and extrahepatic bile ducts down to a level of $2 \mathrm{~cm}$ above the duodenum where there was a sharply defined stricture of the common bile duct suggesting neoplastic infiltration.

Laparotomy was performed on 27 January 1977 and she was found to have a large craggy mass in the head of the pancreas obstructing the lower end of the common bile duct. The mass was believed to be a carcinoma of the head of the pancreas. The gall bladder was distended and full of stones but the liver seemed to be free from tumour and there were no intraperitoneal tumour deposits. A transduodenal biopsy of the pancreatic mass was attempted but histology showed only smooth muscle and connective tissue. The pancreatic mass was not resectable; the gall bladder was emptied of stones and a cholecysto-jejunostomy performed.

The patient recovered uneventfully and went home on the 14th postoperative day. She remained well for four months when she returned to the hospital complaining of severe back pain which was unrelieved by pethidine tablets. Radiography and isotope bone scan of the lumbosacral spine showed no evidence of metastatic disease and liverspleen was normal. It was believed that her pain was caused by the pancreatic lesion and a coeliac plexus block was performed with complete relief of her 
pain. She remained well for four months when she returned with ascites, anaemia, and weight loss. $\mathrm{Hb}$ was $7 \cdot 2 \mathrm{~g} / \mathrm{dl}$ and blood film showed iron deficiency changes. Abdominal paracentesis yielded 4 litres of ascitic fluid and the patient was transfused with packed cells. Both these measures improved her well-being. It was during this admission that her husband died of carcinoma of the pancreas. She remained in reasonable health for only one month when she was admitted for repeat paracentesis and a further blood transfusion. Thereafter, her general condition gradually deteriorated and, over the next four months, she required a total of five paracenteses and three blood transfusions. In February 1978, 13 months after the onset of her symptoms, she died at home from bronchopneumonia. As she died at home and the family had lost both parents in the space of four months, permission for necropsy was not obtained.

THE HUSBAND

Mr J D was an immigrant Dutch carpenter who presented in July 1977 with a three week history of epigastric pain radiating through to the back with anorexia, nausea, and general lethargy. It was thought at first that his symptoms were psychological as the patient already knew that his wife had a non-resectable carcinoma of the pancreas. There was a vague history of dyspeptic symptoms 10 years earlier which had resolved with medical treatment, and a recent barium meal performed by his own practitioner was normal. There was no relevant past history.

Mr D smoked an occasional cigar but had never smoked cigarettes. He did not take drugs and drank an occasional glass of red wine. His life-style was unremarkable and he had no unusual hobbies. $\mathrm{He}$ had worked as a carpenter in Adelaide since emigrating to Australia from Holland in 1957. He had trained and worked as a carpenter in Holland. The only unusual dietary features were those he shared with his wife-namely, the ingestion of large amounts of cooking margarine, and the addition of a coffee additive to ground coffee before percolation. Mr D's father had died in his eighth decade, apparently with jaundice, and his mother had died in her 40s from tuberculosis. He had seven brothers all of whom were alive and well in Holland. There was no family history of diabetes or of any other significant illness.

\section{Examination}

The patient showed evidence of recent weight loss and slight pallor. There was epigastric tenderness and the liver edge was palpable two finger-breadths below the right costal margin. Cardiovascular and respiratory systems were normal.

\section{Investigation}

Urinalysis was normal. $\mathrm{Hb} 12.9 \mathrm{~g} / \mathrm{dl}$, WCC 7900 , platelets $279000 / \mathrm{ml}$, coagulation screen normal. Urea and electrolytes normal. Fasting plasma glucose $5.0 \mathrm{mmol} / 1(\mathrm{n}=3 \cdot 9-6 \cdot 1)$, total protein $71 \mathrm{~g} / \mathrm{l}$ $(\mathrm{n}=60-80)$, albumin $44 \mathrm{~g} / \mathrm{l} \quad(\mathrm{n}=32-48)$, bilirubin $12 \mu \mathrm{mol} / \mathrm{l}(\mathrm{n}=3-20)$, alkaline phosphatase $105 \mathrm{U} / \mathrm{l}$ $(n=100-125)$, alanine transferase $5 \mathrm{U} / \mathrm{l}(\mathrm{n}=0-30)$, amylase $150 \mathrm{U} / \mathrm{l}(\mathrm{n}=10-300)$. Endoscopy showed mild reflux oesophagitis but no abnormality of stomach or upper duodenum.

Radiograph of the chest and barium meal were normal. CT scan showed a large retroperitoneal mass in the region of the body of the pancreas and isotope scan of the liver showed multiple filling defects suggesting metastatic deposits. Attempted needle biopsy of the liver yielded only normal liver tissue. To determine the diagnosis, a laparotomy was performed on 20 September 1977 and the patient was found to have a large, fixed, hard, irregular mass affecting the body and tail of the pancreas. The head of the pancreas and, consequently, the lower end of the common bile duct were spared, but there were numerous large umbilicated hepatic metastases and widespread deposits of tumour throughout the visceral and parietal peritoneum. No definitive procedure was performed but biopsy of liver and of peritoneal deposit confirmed the macroscopic diagnosis of metastatic carcinoma arising from the pancreas.

Postoperatively, an alcoholic coeliac plexus block was performed with reasonable relief of his pain. Mr J D was allowed home and remained fairly well for a period of two months when he was readmitted with recurrent abdominal pain, ascites, and cachexia. Treatment was symptomatic and two weeks later he died from generalised carcinomatosis. Necropsy confirmed the diagnosis of adenocarcinoma of the body of the pancreas with widespread peritoneal and hepatic metastases.

\section{Discussion}

We report here the simultaneous occurence of pancreatic cancer in husband and wife. Although there was no histological proof of the diagnosis in Mrs P D, the operative findings and the subsequent clinical progression to cachexia and death left little doubt that the lesion was a pancreatic cancer. The two dietary idiosyncrasies demonstrated by both patients were sufficiently unusual to prevent the children of the family from conforming with them. The following information was obtained from the family.

The parents cooked the main course of their evening meal in such a copious amount of cooking 
margarine that, once the food had been removed from the pan, there was enough margarine left to be made into a thick sauce which was then poured over the meal on the plate. This habit was so excessive that the children, once they had reached their teens, refused to eat the margarine sauce.

'Coffee syrup' is a liquid concentrate of coffee which is added to ground coffee before percolation in order to give it a stronger flavour. This is quite a common practice in Europe but, again, the children of this family found the coffee which their parents percolated much too strong and they made their own separate pot of coffee.

The simultaneous occurrence of pancreatic cancer in husband and wife has not previously been reported, although McCarthy and Espiner ${ }^{1}$ did report cancer of the common bile duct occurring simultaneously in a married couple. The aetiology of pancreatic cancer is unclear and, although association with diabetes ${ }^{23}$, chronic pancreatitis ${ }^{4}$ and alcoholism ${ }^{5}$ have been reported, there is no good evidence that any of these conditions predisposes to pancreatic cancer. The increasing incidence ${ }^{6}$ and the geographical and racial variations ${ }^{7}$ in the incidence of pancreatic cancer, point to causal agents in the environment. ${ }^{7}$ Pancreatic cancer has been induced in rats, guinea-pigs, and mice with a variety of chemicals such as methyl nitrosamine ${ }^{5}$ and $\mathrm{Li}$ et $\mathrm{al}^{\mathrm{8}}$ reported an increased incidence of pancreatic and other alimentary cancers in a study of 3500 workers from an American Chemical Society. The risk of pancreatic cancer is 2.5 times greater and the age of onset 10 years younger in smokers than in non-smokers. ${ }^{9}{ }^{10}$ Reimer et al. ${ }^{11}$ suggest that pistachio nuts contaminated with mycotoxins were implicated in the causation of pancreatic cancer in a father and son, and McCarthy and Espiner ${ }^{1}$ suggest that eating excessive amounts of carraway seed, contaminated with aflatoxin, might be a possible aetiological factor in cancer of the common bile duct occurring in husband and wife.

Coffee and the role of caffeine in carcinogenesis has been the topic of much debate in recent years. Simon et al. ${ }^{12}$ reported a high incidence of urinary tract cancer in coffee drinkers but Armstrong et al. ${ }^{13}$ failed to substantiate this finding. Challis and Bartlett ${ }^{14}$ demonstrated that the conversion of nitrites to carcinogenic nitrosamines was catalysed by readily oxidisable compounds similar in structure to chlorogenic acid, which comprises about $13 \%$ by weight of most standard household coffees. Thus, nitrite salts derived from nitrite-preserved foodstuffs could be converted into carcinogenic nitrosamines in the stomach by the catalyic action of the chlorogenic acid in coffee. Indeed, Mori and Hirono ${ }^{15}$ demonstrated an enhancement of the carcinogenicity of cycasin in rats by addition of chlorogenic acid and postulate a co-carcinogenic effect of chlorogenic acid. It is interesting that, in our patients, one of the dietary abnormalities displayed was the addition of concentrated coffee syrup to ground coffee before percolation.

\section{Conclusion}

We report the simultaneous occurrence in husband and wife of pancreatic cancer. The only two dietary abnormalities detected were ingestion of excessive quantities of cooking margarine and the addition of coffee syrup to ground coffee before percolation. Margarine has been largely cleared from involvement in carcinogenesis since the removal of the colouring agent 'butter yellow' from the market. Coffee, on the other hand, has been implicated by both epidemiological and experimental studies, and, although none of the evidence is particularly convincing, it may be that the ingestion of excessive amounts of 'coffee syrup' contributed in some way to the development of the pancreatic cancers. However, the use of 'coffee syrup' is not a gross deviation from the norm and it may be quite incidental. It is interesting that both patients developed their cancers at approximately the same time and it is attractive to argue promotion of carcinogenesis by some recent environmental agent-for example, a virusin an organ in which potential carcinogenesis had already been induced by prolonged exposure to another agent.

\section{References}

${ }^{1}$ McCarthy CF, Espiner HJ. Carcinoma of bile ducts in husband and wife. Gut 1969; 10: 94-7.

${ }^{2}$ Ellinger F, Landsman H. Frequency and course of cancer in diabetics. N Y State J Med 1944; 44: 259-65.

${ }^{3}$ Green RC Jr, Bagenstoss AH, Sprague RG. Diabetes mellitus in association with primary carcinoma of the pancreas. Diabetes 1958; 7: 308-311.

${ }^{4}$ Johnson JR, Zintel HA. Pancreatic calcification and cancer of the pancreas. Surg Gynecol Obstet 1963; 117: 585-8.

${ }^{5}$ Mainz D, Webster PD. Pancreatic carcinoma-a review of etiologic considerations. Digestive Diseases 1974; 19: 459-464.

${ }^{6}$ Levin DL, Connelly RR. Cancer of the pancreasavailable epidemiological information and its implications. Cancer 1972; 31 : 1231-36.

${ }^{7}$ Wynder EL, Reddy BS, McCoy GD, Weisburger JH, Williams GM. Diet and gastrointestinal cancer. Clin Gastroenterol 1976; 5: 463-82. 
${ }^{8} \mathrm{Li}$ FP, Fraumeni JF Jr, Mantel. N, Miller RW. Cancer mortality among chemists. J Natl Cancer Inst 1969; 43: 1159-64.

${ }^{9} \mathrm{Hammond}$ EC. Trends in cancer death rates and cure rates. Ann Intern Med 1959; 50: 300-12.

${ }^{10}$ Wynder EL, Mabuchi K, Maruchi N, Fortner JG. Epidemiology of cancer of the pancreas. $J$ Natl Cancer Inst 1973; 50: 645-67.

"Reimer R, Fraumeni JF Jr, Ozols RF, Bender R. Pancreatic cancer in father and son. Lancet 1977; 1: 911. (Letter.)
${ }^{12}$ Simon D, Yen S, Cole P. Coffee drinking and cancer of the lower urinary tract. J Natl Cancer Inst 1975 54: (3): 587-91.

${ }^{13}$ Armstrong B, Garrod A, Doll R. A retrospective study of renal cancer with special reference to coffee and animal protein consumption. $B r J$ Cancer 1976; 33 (2): $127-36$.

${ }^{14}$ Challis BC, Bartlett CD. Possible cocarcinogenic effects of coffee constituents. Nature 1975; 254: 532-33.

${ }^{15}$ Mori H, Hirono I. Effect of coffee on carcinogenicity of cycasin. Brit J Cancer 1977; 35: 369-71. 